\title{
The Tigecycline Evaluation and Surveillance Trial; assessment of the activity of tigecycline and other selected antibiotics against Gram-positive and Gram-negative pathogens from France collected between 2004 and 2016
}

Jean-Winoc Decousser ${ }^{1 *}$, Paul-Louis Woerther ${ }^{1}$, Claude-James Soussy ${ }^{1}$, Marguerite Fines-Guyon ${ }^{2}$ and Michael J. Dowzicky ${ }^{3}$

\begin{abstract}
Background: A high level of antibiotic consumption in France means antimicrobial resistance requires rigorous monitoring. The Tigecycline Evaluation and Surveillance Trial (T.E.S.T.) is a global surveillance study that monitors the in vitro activities of tigecycline and a panel of marketed antimicrobials against clinically important Gram-positive and Gram-negative isolates.

Methods: Annually clinically relevant strains were prospectively included in the survey through a national network of hospital-based laboratories. MICs were determined locally by broth microdilution using CLSI guidelines. Antimicrobial susceptibility was assessed using European Committee on Antimicrobial Susceptibility Testing breakpoints.

Results: Thirty-three centres in France collected 26,486 isolates between 2004 and 2016. Enterococcus species were highly susceptible ( $\geq 94.4 \%)$ to linezolid, tigecycline and vancomycin. Staphylococcus aureus, including methicillin-resistant $S$. aureus (MRSA), were susceptible ( $\geq 99.9 \%$ ) to tigecycline, vancomycin and linezolid. Between 2004 and 2016, 27.7\% of S. aureus isolates were MRSA, decreasing from 28.0\% in 2013 to 23.5\% in 2016. Susceptibility of Streptococcus pneumoniae isolates was 100\% to vancomycin, and $>99.0 \%$ to levofloxacin, linezolid and meropenem; $3.0 \%$ were penicillin-resistant $S$. pneumoniae (100\% susceptibility to vancomycin and linezolid). Escherichia coli isolates were highly susceptible (>98.0\%) to meropenem, tigecycline and amikacin. The rate of extended-spectrum $\beta$-lactamase (ESBL) positive E. coli increased from 2004 (3.0\%), but was stable from 2012 (23.1\%) to 2016 (19.8\%). Susceptibility of Klebsiella pneumoniae isolates was 99.4\% to meropenem and $96.5 \%$ to amikacin. The proportion of ESBL-positive $K$. pneumoniae isolates increased from 2004 (7.5\%) to 2012 (33.3\%) and was highest in 2016 (43.6\%). A. baumannii was susceptible to meropenem (81.0\%) and amikacin (74. $9 \%)$; none of the $6.2 \%$ of isolates identified as multidrug-resistant (MDR) was susceptible to any agents with breakpoints. P. aeruginosa isolates were most susceptible to amikacin (88.5\%), and MDR rates were 13.6\% in 2013 to $4.0 \%$ in 2016; susceptibility of MDR isolates was no higher than $31.4 \%$ to amikacin.

(Continued on next page)
\end{abstract}

* Correspondence: jean-winoc.decousser@aphp.fr

'University Hospital Henri Mondor, 9400 Creteil, France

Full list of author information is available at the end of the article

(c) The Author(s). 2018 Open Access This article is distributed under the terms of the Creative Commons Attribution 4.0 International License (http://creativecommons.org/licenses/by/4.0/), which permits unrestricted use, distribution, and reproduction in any medium, provided you give appropriate credit to the original author(s) and the source, provide a link to the Creative Commons license, and indicate if changes were made. The Creative Commons Public Domain Dedication waiver (http://creativecommons.org/publicdomain/zero/1.0/) applies to the data made available in this article, unless otherwise stated. 
(Continued from previous page)

Conclusions: Rates of MRSA decreased slowly, while rates of ESBL-positive E. coli and K. pneumoniae increased from 2004 to 2016. Susceptibility of Gram-positive isolates to vancomycin, tigecycline, meropenem and linezolid was well conserved, as was susceptibility of Gram-negative isolates to tigecycline and meropenem. The spread of MDR non-fermentative isolates must be carefully monitored.

Keywords: France, Gram-positive, Gram-negative, Multidrug-resistance, Antimicrobial surveillance, Tigecycline

\section{Background}

Despite significant efforts to reduce antibiotic use, France has one of the highest rates of antimicrobial consumption in the community in Europe [1], and has seen considerable changes in trends of antibacterial resistance during recent years [2-5]. In France, resistance to antibiotics has been monitored since 2002 by the French national healthcare-associated infection early warning, investigation and surveillance network (RAISIN), which recently reported a $182 \%$ increase in the prevalence of extended-spectrum $\beta$-lactamase (ESBL)-producing Enterobacteriaceae during nine years [2]. Extensively drug-resistant bacteria such as vancomycin-resistant enterococci (VRE) and carbapenemase-producing Enterobacteriaceae (CPE) are not endemic in France, although VRE are disseminated in neighbouring countries such as Italy and Germany, and CPE are considered endemic in Italy [6, 7]. Methicillin-resistant Staphylococcus aureus (MRSA) rates in France have been considered to be decreasing during the decade from 2000 to 2010 and in subsequent years $[3,8,9]$, and this is consistent with reduced MRSA rates reported in Germany since 2007 [3, 10-12] and from 2010 in the UK $[3,13]$. The situation regarding antimicrobial resistance in France requires rigorous monitoring, particularly for second-line antimicrobial compounds and clinically relevant bacterial species. To meet the challenge presented by antimicrobial resistance, authorities in France have developed a number of national initiatives that include antibiotic stewardship in hospitals and surveillance of antibiotic use [14].

The broad-spectrum antimicrobial agent tigecycline is indicated for the treatment of complicated skin and soft tissue infections (cSSTIs), excluding diabetic foot infections, and complicated intra-abdominal infections (cIAIs), and, in the USA, community-acquired bacterial pneumonia $[15,16]$. The Tigecycline Evaluation and Surveillance Trial (T.E.S.T.) was instigated in 2004 with the intention of global surveillance of antimicrobial activity of tigecycline and a panel of other antimicrobial agents against an array of clinically important Gram-positive and Gram-negative pathogens. In this study, we report an update to that provided by Cattoir and Dowzicky [17] regarding the in vitro susceptibility to tigecycline and comparators of isolates collected from community or hospitalized patients in France between 2004 and 2016.

\section{Methods}

Materials and methods for isolates collected as part of the T.E.S.T. study in France have been published previously [17], with minimum inhibitory concentrations (MICs) determined locally according to the broth microdilution method described by the Clinical and Laboratory Standards Institute (CLSI) [18, 19].

Isolates were collected if considered to be of clinical significance as the probable causative agent of a hospital- or community-acquired infection. Isolates were accepted from all body sites, including the following sources: samples of body fluids (classified as abdominal, ascites, bile, paracentesis, peritoneal), central nervous system, cardiovascular system, gastrointestinal (GI) sources (abscess, appendix, diverticulum, oesophagus, faeces/stool, gall bladder, large colon, liver, pancreas, rectum, small colon, stomach, general GI or other GI), genito-urinary, head, ears, eyes, nose and throat, integument, lymph, muscular, reproductive, respiratory, skeletal or medical instruments (i.e. catheters, drains, forceps, probes). Duplicate isolates from a single patient were not accepted.

Coordination of isolate collection and transport was carried out by International Health Management Associates (IHMA), Schaumburg, IL, USA. The panel of antimicrobial agents for the T.E.S.T. study included an aminoglycoside (amikacin), agents in the penicillin class (ampicillin, amoxicillin-clavulanate, penicillin, piperacillin-tazobactam), cephalosporins (cefepime, ceftazidime, ceftriaxone) a carbapenem (imipenem), a fluoroquinolone (levofloxacin), an oxazolidinone (linezolid), a tetracycline (minocycline), a glycylcycline (tigecycline) and a glycopeptide (vancomycin). In 2006, meropenem replaced imipenem due to stability issues associated with imipenem testing, and the $S$. pneumoniae test panel was expanded to include three macrolides (azithromycin, clarithromycin, erythromycin) and a lincosamide (clindamycin), with isolates tested retrospectively for susceptibility to these agents wherever possible. Antimicrobial susceptibility of aerobic isolates was performed using the breakpoints established by the European Committee on Antimicrobial Susceptibility Testing (EUCAST) [20]. Susceptibility data are included in the tables only when interpretive breakpoints are available. Methicillin resistance in $S$. aureus and ESBL-production among E. coli and Klebsiella spp. were determined by IHMA according to CLSI 
guidelines [19]. As specified in a previous T.E.S.T. study [21], isolates that were resistant to three or more classes of antimicrobial agents were defined as multidrug-resistant (MDR). Classes used to define MDR A. baumannii were aminoglycosides (amikacin), $\beta$-lactams (cefepime, ceftazidime, ceftriaxone or piperacillin-tazobactam), carbapenems (imipenem/meropenem), fluoroquinolones (levofloxacin) and tetracyclines (minocycline), and the classes used to define MDR $P$. aeruginosa were aminoglycosides (amikacin), $\beta$-lactams (cefepime, ceftazidime, or piperacillin-tazobactam), carbapenems (imipenem/meropenem), and fluoroquinolones (levofloxacin) [21].

The Cochran Armitage Trend Test was used to identify statistically significant changes in susceptibility between 2004 and 2016, and results with a $p$-value of $<0.01$ were deemed significant.

\section{Results}

A total of 26,486 isolates were collected from 33 centres in France between 2004 and 2016 (eight in 2004, six in 2005, 12 in 2006, 16 in 2007, 21 in 2008, 20 in 2009, 16 in 2010 and 2011, 14 in 2012, 12 in 2013 and 2014, 11 in 2015 and four in 2016).

\section{Gram-positives}

\section{Enterococcus spp}

All isolates of $E$. faecalis $(N=1429)$ were highly susceptible $(\geq 98.4 \%)$ to ampicillin, linezolid, tigecycline and vancomycin (Table 1). All isolates of VRE E. faecalis $(N=11,0.8 \%)$ were susceptible to tigecycline and 90.9\% were susceptible to linezolid. Between 2004 and 2016, 537 isolates of E. faecium were collected, which included $410(76.4 \%)$ ampicillin-resistant isolates. All isolates were highly susceptible to tigecycline (100\%), linezolid (99.8\%) and vancomycin $(94.4 \%)$ (Table 1$)$. Thirty E. faecium isolates (5.6\%) were identified as VRE, which were $100 \%$ susceptible to linezolid and tigecycline.

\section{S. aureus}

All $S$. aureus isolates $(N=3437)$ were susceptible to tigecycline and vancomycin (Table 1). Susceptibility to linezolid was $>99.9 \%$, to minocycline $95.0 \%$ and to levofloxacin $73.2 \%$. The proportion of isolates identified as MRSA $(N=953)$ between 2004 to 2016 was $27.7 \%$ (range, 18.3-34.3\%) and during the period 2013 to 2016 decreased from 28.0 to $23.5 \%$ (Table 2). All MRSA isolates were susceptible to linezolid, tigecycline and vancomycin (Table 1), and susceptibility to minocycline was 94.2\%. The susceptibility of MRSA isolates collected between 2004 and 2016 to levofloxacin was relatively low, at $16.7 \%$. A vancomycin MIC of $>1 \mathrm{mg} / \mathrm{L}$ was observed in $35(3.7 \%)$ of the MRSA isolates, and of these, $2.9 \%$ were susceptible to levofloxacin, and $74.3 \%$ to minocycline. MRSA isolates that exhibited a vancomycin
MIC that was $\leq 1 \mathrm{mg} / \mathrm{L}(N=918)$ exhibited susceptibility of $17.2 \%$ to levofloxacin and $95.0 \%$ to minocycline.

\section{S. agalactiae}

Susceptibility of $S$. agalactiae isolates $(N=1348)$ was $100 \%$ to linezolid, penicillin and vancomycin; isolates were also highly susceptible to tigecycline (99.8\%), and to levofloxacin (99.1\%).

\section{S. pneumoniae}

A total of 1684 isolates of S. pneumoniae were collected during the study, and all were susceptible to vancomycin, with $>99.6 \%$ of isolates susceptible to levofloxacin, linezolid and meropenem ( $N=1557$ for meropenem). Tigecycline exhibited an in vitro $\mathrm{MIC}_{90}$ value of $0.06 \mathrm{mg} / \mathrm{L}$ against $S$. pneumoniae isolates, and during the study there was a statistically significant increase $(p<0.0001)$ in susceptibility to azithromycin (2004, 50.0\%; 2016, 76.2\%), clarithromycin (2004, 50.0\%; 2016, 78.6\%), clindamycin (2004, 52.3\%; 2016, $83.3 \%$ ) and erythromycin (2004, 50.0\%; 2016, 78.6\%), and also to minocycline $(p<0.01 ; 2004,52.7 \%$; 2016, 78.6\%). A total of 51 (3.0\%) penicillin-resistant $S$. pneumoniae isolates were collected between 2004 to 2016 and all of these were susceptible to vancomycin and linezolid. Rates of penicillin-resistant S. pneumoniae susceptibility to levofloxacin (98.0\%) and meropenem (94.1\%) were relatively high and stable; the $\mathrm{MIC}_{90}$ of tigecycline was $0.03 \mathrm{mg} / \mathrm{L}$. Penicillin-resistant $S$. pneumoniae isolates collected between 2013 and 2016 and tested for susceptibility to erythromycin $(N=13)$ and minocycline $(N=14)$ showed susceptibility rates of 38.5 and $21.4 \%$, respectively, which were lower compared with all $S$. pneumoniae isolates that were collected during the same period and tested against erythromycin $(N=473$, $66.4 \%$ susceptibility) and minocycline $(N=496,61.7 \%$ susceptibility).

\section{Gram-negatives \\ Enterobacter spp}

The agent with the lowest in vitro $\mathrm{MIC}_{90}$ value against Enterobacter spp. isolates $(N=3424)$ was meropenem $\left(\mathrm{MIC}_{90} 0.25 \mathrm{mg} / \mathrm{L}\right)$, to which $99.2 \%$ of isolates were susceptible (Table 3). Susceptibility to amikacin (96.9\%) and tigecycline $(86.3 \%)$ was stable, and susceptibility to levofloxacin was $71.5 \%$. A lower proportion of isolates were susceptible to the cephalosporins on the T.E.S.T. panel, cefepime (69.5\%) and ceftriaxone (50.9\%).

\section{E. coli}

Isolates of E. coli $(N=3527)$ were highly susceptible to meropenem (99.9\%), tigecycline $(99.4 \%)$ and amikacin $(98.1 \%)$ (Table 3 ). The susceptibility of $E$. coli isolates to piperacillin-tazobactam (89.6\%) was 
Table 1 Minimum inhibitory concentrations ( $\mathrm{MIC}_{90}$, MIC range $[\mathrm{mg} / \mathrm{L}]$ ) and antimicrobial susceptibility (\%S) and resistance (\%R) of Gram-positive isolates

\begin{tabular}{|c|c|c|c|c|c|c|c|c|}
\hline \multirow[t]{2}{*}{ Organism/ Antimicrobial } & \multicolumn{4}{|l|}{ 2004-2016 } & \multicolumn{4}{|l|}{ 2013-2016 } \\
\hline & $\mathrm{MIC}_{90}(\mathrm{mg} / \mathrm{L})$ & MIC Range (mg/L) & $\% \mathrm{~S}$ & $\% R$ & $\mathrm{MIC}_{90}(\mathrm{mg} / \mathrm{L})$ & MIC Range (mg/L) & $\% \mathrm{~S}$ & $\% R$ \\
\hline E. faecalis & \multicolumn{4}{|l|}{$N=1429$} & \multicolumn{4}{|l|}{$N=373$} \\
\hline Ampicillin $^{a}$ & 2 & $\leq 0.06$ to $\geq 32$ & 98.4 & 1.0 & 1 & $\leq 0.06$ to $\geq 32$ & 97.1 & 2.1 \\
\hline Linezolid & 2 & $\leq 0.5$ to $\geq 16$ & 99.9 & 0.1 & 2 & $\leq 0.5$ to $\geq 16$ & 99.7 & 0.3 \\
\hline Tigecycline & 0.25 & $\leq 0.008$ to 0.5 & 99.9 & 0.0 & 0.12 & 0.03 to 0.25 & 100 & 0.0 \\
\hline Vancomycin & 2 & 0.25 to $\geq 64$ & 99.2 & 0.8 & 2 & 0.25 to $\geq 64$ & 99.2 & 0.8 \\
\hline E. faecalis, VRE & \multicolumn{4}{|l|}{$N=11$} & \multicolumn{4}{|l|}{$N=3$} \\
\hline Amox-clav & $\geq 16$ & 0.25 to $\geq 16$ & 81.8 & 18.2 & $\geq 16$ & 0.5 to $\geq 16$ & {$[1]$} & {$[2]$} \\
\hline Ampicillin & $\geq 32$ & 0.5 to $\geq 32$ & 81.8 & 18.2 & $\geq 32$ & 1 to $\geq 32$ & {$[1]$} & {$[2]$} \\
\hline Linezolid & 2 & 1 to $\geq 16$ & 90.9 & 9.1 & $\geq 16$ & 1 to $\geq 16$ & {$[2]$} & {$[1]$} \\
\hline Tigecycline & 0.25 & 0.06 to 0.25 & 100 & 0.0 & 0.25 & 0.06 to 0.25 & [3] & {$[0]$} \\
\hline E. faecium & \multicolumn{4}{|l|}{$N=537$} & \multicolumn{4}{|l|}{$N=159$} \\
\hline Linezolid & 2 & $\leq 0.5$ to 8 & 99.8 & 0.2 & 2 & $\leq 0.5$ to 8 & 99.4 & 0.6 \\
\hline Tigecycline & 0.25 & 0.015 to 0.25 & 100 & 0.0 & 0.12 & 0.015 to 0.25 & 100 & 0.0 \\
\hline Vancomycin & 2 & 0.25 to $\geq 64$ & 94.4 & 5.6 & 1 & 0.25 to $\geq 64$ & 98.1 & 1.9 \\
\hline E. faecium, VRE & \multicolumn{4}{|l|}{$N=30$} & \multicolumn{4}{|l|}{$N=3$} \\
\hline Linezolid & 2 & 1 to 2 & 100 & 0.0 & 2 & 1 to 2 & {$[3]$} & {$[0]$} \\
\hline Tigecycline & 0.25 & 0.03 to 0.25 & 100 & 0.0 & 0.25 & 0.06 to 0.25 & [3] & {$[0]$} \\
\hline S. aureus & \multicolumn{4}{|l|}{$N=3437$} & \multicolumn{4}{|l|}{$N=947$} \\
\hline Levofloxacin $^{\text {b }}$ & 32 & $\leq 0.06$ to $\geq 64$ & 73.2 & 26.8 & 16 & $\leq 0.06$ to $\geq 64$ & 76.7 & 23.3 \\
\hline Linezolid & 2 & $\leq 0.5$ to 8 & $>99.9$ & $<0.1$ & 2 & $\leq 0.5$ to 8 & 99.9 & 0.1 \\
\hline Minocycline ${ }^{b}$ & 0.5 & $\leq 0.25$ to $\geq 16$ & 95.0 & 3.0 & $\leq 0.25$ & $\leq 0.25$ to $\geq 16$ & 97.5 & 2.1 \\
\hline Penicillin & $\geq 16$ & $\leq 0.06$ to $\geq 16$ & 15.0 & 85.0 & $\geq 16$ & $\leq 0.06$ to $\geq 16$ & 16.6 & 83.4 \\
\hline Tigecycline & 0.25 & $\leq 0.008$ to 0.5 & 100 & 0.0 & 0.12 & 0.015 to 0.5 & 100 & 0.0 \\
\hline Vancomycin & 1 & $\leq 0.12$ to 2 & 100 & 0.0 & 1 & 0.25 to 2 & 100 & 0.0 \\
\hline S. aureus, MRSA & \multicolumn{4}{|l|}{$N=953$} & \multicolumn{4}{|l|}{$N=234$} \\
\hline Levofloxacin ${ }^{b}$ & $\geq 64$ & $\leq 0.06$ to $\geq 64$ & 16.7 & 83.3 & 32 & 0.12 to $\geq 64$ & 17.5 & 82.5 \\
\hline Linezolid & 2 & $\leq 0.5$ to 4 & 100 & 0.0 & 4 & $\leq 0.5$ to 4 & 100 & 0.0 \\
\hline Minocycline ${ }^{b}$ & 0.5 & $\leq 0.25$ to $\geq 16$ & 94.2 & 4.6 & $\leq 0.25$ & $\leq 0.25$ to 8 & 95.3 & 3.8 \\
\hline Penicillin & $\geq 16$ & 0.5 to $\geq 16$ & 0.0 & 100 & $\geq 16$ & 0.25 to $\geq 16$ & 0.0 & 100 \\
\hline Tigecycline & 0.25 & 0.015 to 0.25 & 100 & 0.0 & 0.25 & 0.015 to 0.5 & 100 & 0.0 \\
\hline Vancomycin & 1 & $\leq 0.12$ to 2 & 100 & 0.0 & 1 & 0.25 to 2 & 100 & 0.0 \\
\hline S. agalactiae & \multicolumn{4}{|l|}{$N=1348$} & \multicolumn{4}{|l|}{$N=378$} \\
\hline Levofloxacin & 1 & $\leq 0.06$ to 32 & 99.1 & 0.9 & 1 & 0.12 to 32 & 97.9 & 2.1 \\
\hline Linezolid & 1 & $\leq 0.5$ to 2 & 100 & 0.0 & 1 & $\leq 0.5$ to 2 & 100 & 0.0 \\
\hline Minocycline & $\geq 16$ & $\leq 0.25$ to $\geq 16$ & 16.1 & 82.0 & $\geq 16$ & $\leq 0.25$ to $\geq 16$ & 15.6 & 83.1 \\
\hline Penicillin & 0.12 & $\leq 0.06$ to 0.12 & 100 & 0.0 & 0.12 & $\leq 0.06$ to 0.12 & 100 & 0.0 \\
\hline Tigecycline & 0.12 & 0.015 to 4 & 99.8 & 0.1 & 0.12 & 0.015 to 4 & 99.7 & 0.3 \\
\hline Vancomycin & 0.5 & $\leq 0.12$ to 1 & 100 & 0.0 & 0.5 & $\leq 0.12$ to 1 & 100 & 0.0 \\
\hline S. pneumoniae & \multicolumn{4}{|c|}{$N=1684(\mathrm{AZM}, \mathrm{CLR}, \mathrm{CLI}, \mathrm{ERY}, N=1500)$} & \multicolumn{4}{|c|}{$N=496(A Z M, C L R, C L I, E R Y, N=473)$} \\
\hline Azithromycin $^{\mathrm{b}}$ & $\geq 128$ & $\leq 0.03$ to $\geq 128$ & 60.5 & 39.1 & $\geq 128$ & $\leq 0.03$ to $\geq 128$ & 65.8 & 33.8 \\
\hline Ceftriaxone & 1 & $\leq 0.03$ to 16 & 80.8 & 0.5 & 1 & $\leq 0.03$ to 2 & 84.7 & 0.0 \\
\hline Clarithromycin ${ }^{b}$ & $\geq 128$ & $\leq 0.015$ to $\geq 128$ & 60.9 & 38.5 & $\geq 128$ & $\leq 0.015$ to $\geq 128$ & 66.4 & 32.6 \\
\hline
\end{tabular}


Table 1 Minimum inhibitory concentrations ( $\mathrm{MIC}_{90}, \mathrm{MIC}$ range $[\mathrm{mg} / \mathrm{L}]$ ) and antimicrobial susceptibility (\%S) and resistance (\%R) of Gram-positive isolates (Continued)

\begin{tabular}{|c|c|c|c|c|c|c|c|c|}
\hline \multirow[t]{2}{*}{ Organism/ Antimicrobial } & \multicolumn{4}{|l|}{$2004-2016$} & \multicolumn{4}{|l|}{$2013-2016$} \\
\hline & $\mathrm{MIC}_{90}(\mathrm{mg} / \mathrm{L})$ & MIC Range (mg/L) & $\% \mathrm{~S}$ & $\% \mathrm{R}$ & $\mathrm{MIC}_{90}(\mathrm{mg} / \mathrm{L})$ & MIC Range (mg/L) & $\% \mathrm{~S}$ & $\% R$ \\
\hline Clindamycin $^{\mathrm{b}}$ & $\geq 128$ & $\leq 0.015$ to $\geq 128$ & 68.5 & 31.5 & $\geq 128$ & $\leq 0.015$ to $\geq 128$ & 71.9 & 28.1 \\
\hline Erythromycin ${ }^{b}$ & $\geq 128$ & $\leq 0.015$ to $\geq 128$ & 60.6 & 38.7 & $\geq 128$ & $\leq 0.015$ to $\geq 128$ & 66.4 & 33.2 \\
\hline Levofloxacin & 1 & $\leq 0.06$ to $\geq 64$ & 99.7 & 0.3 & 1 & $\leq 0.06$ to 2 & 100 & 0.0 \\
\hline Linezolid & 1 & $\leq 0.5$ to 4 & 99.9 & 0.0 & 1 & $\leq 0.5$ to 2 & 100 & 0.0 \\
\hline Meropenem $(N=1557)^{c}$ & 0.5 & $\leq 0.12$ to $\geq 32$ & 99.8 & 0.2 & 1 & $\leq 0.12$ to 8 & 99.8 & 0.2 \\
\hline Minocycline $^{b}(N=1683)$ & 8 & $\leq 0.25$ to $\geq 16$ & 52.4 & 38.6 & 8 & $\leq 0.25$ to $\geq 16$ & 61.7 & 31.9 \\
\hline Penicillin & 2 & $\leq 0.06$ to $\geq 16$ & 53.0 & 3.0 & 2 & $\leq 0.06$ to 8 & 53.4 & 2.8 \\
\hline Tigecycline & 0.06 & $\leq 0.008$ to 0.5 & - & - & 0.03 & $\leq 0.008$ to 0.06 & - & - \\
\hline Vancomycin & 0.5 & $\leq 0.12$ to 1 & 100 & 0.0 & 0.5 & $\leq 0.12$ to 1 & 100 & 0.0 \\
\hline S. pneumoniae, PRSP & \multicolumn{4}{|c|}{$N=51(A Z M, C L R, C L I, E R Y, N=48)$} & \multicolumn{4}{|c|}{$N=14(\mathrm{AZM}, \mathrm{CLR}, \mathrm{CLI}, \mathrm{ERY}, \mathrm{N}=14)$} \\
\hline Azithromycin & $\geq 128$ & $\leq 0.03$ to $\geq 128$ & 22.9 & 77.1 & $\geq 128$ & 0.06 to $\geq 128$ & 38.5 & 61.5 \\
\hline Ceftriaxone & 2 & $\leq 0.03$ to 8 & 9.8 & 9.8 & 2 & $\leq 0.03$ to 2 & 21.4 & 0 \\
\hline Clarithromycin & $\geq 128$ & $\leq 0.015$ to $\geq 128$ & 22.9 & 77.1 & $\geq 128$ & $\leq 0.015$ to $\geq 128$ & 38.5 & 61.5 \\
\hline Clindamycin & $\geq 128$ & $\leq 0.015$ to $\geq 128$ & 37.5 & 62.5 & $\geq 128$ & 0.03 to $\geq 128$ & 46.2 & 53.8 \\
\hline Erythromycin & $\geq 128$ & $\leq 0.015$ to $\geq 128$ & 22.9 & 75.0 & $\geq 128$ & 0.03 to $\geq 128$ & 38.5 & 61.5 \\
\hline Levofloxacin & 1 & 0.25 to 16 & 98.0 & 2.0 & 1 & 0.5 to 1 & 100 & 0.0 \\
\hline Linezolid & 1 & $\leq 0.5$ to 2 & 100 & 0.0 & 1 & $\leq 0.5$ to 2 & 100 & 0.0 \\
\hline Meropenem ${ }^{c}$ & 2 & $\leq 0.12$ to $\geq 32$ & 94.1 & 5.9 & 2 & $\leq 0.12$ to 8 & 92.9 & 7.1 \\
\hline Minocycline & $\geq 16$ & $\leq 0.25$ to $\geq 16$ & 19.6 & 70.6 & 8 & $\leq 0.25$ to $\geq 16$ & 21.4 & 64.3 \\
\hline Tigecycline & 0.03 & 0.015 to 0.12 & - & - & 0.03 & 0.015 to 0.03 & - & - \\
\hline Vancomycin & 0.5 & 0.25 to 1 & 100 & 0.0 & 0.5 & 025 to 1 & 100 & 0.0 \\
\hline
\end{tabular}

${ }^{a}$ indicates statistically significant decrease in susceptibility $(p<0.01)$ from 2004 to 2016

${ }^{\mathrm{b}}$ indicates statistically significant increase in susceptibility $(p<0.01)$ from 2004 to 2016

c Meropenem was introduced to the testing panel in 2006, replacing imipenem; N values of activity against organisms collected from 2006 to 2016 are given Amox-clav, amoxicillin-clavulanic acid, $A Z M$, azithromycin, $C L R$, clarithromycin, $C L I$, clindamycin, $E R Y$, erythromycin, $M I C$, minimum inhibitory concentration, $M I C_{90}$, minimum inhibitory concentration required to inhibit growth of $90 \%$ of isolates (mg/L), MRSA, methicillin-resistant S. aureus, Pip-taz, piperacillin-tazobactam, PRSP, Penicillin-resistant $S$. pneumoniae, $R$, resistant, $S$, susceptible, VRE, vancomycin-resistant enterococci

relatively stable, but there was a decline in susceptibility to levofloxacin $(92.1 \%$ in 2004 to $76.2 \%$ in 2016) and statistically significant declines in susceptibility to cefepime $(97.0 \%$ in 2004 to $77.2 \%$ in 2016 ; $p<0.0001)$ and ceftriaxone $(96.0 \%$ in 2004 to $78.2 \%$ in 2016; $p<0.0001$ ).

The proportion of $E$. coli isolates identified as ESBL-positive E. coli between 2004 and 2016 $(N=489)$ was $13.9 \%$. This is lower than the annual rates between 2013 (14.9\%) and 2016 (19.8\%), although these were stable (Table 2). Susceptibility of all ESBL-positive $E$. coli isolates was $99.2 \%$ to tigecycline, $92.6 \%$ to amikacin, and $100 \%$ to meropenem for the 472 isolates tested from 2006 onwards. Susceptibility of ESBL-positive E. coli to piperacillin-tazobactam (78.3\%) was lower compared with all isolates of E. coli (89.6\%), and only $37.8 \%$ of ESBL-positive E. coli isolates were susceptible to levofloxacin and $45.8 \%$ to amoxicillin-clavulanate; no isolates were susceptible to ceftriaxone and $3.9 \%$ were susceptible to cefepime.

Table 2 Percentages of resistant phenotypes among Gram-positive and Gram-negative isolates by year, 2013-2016

\begin{tabular}{|c|c|c|c|c|c|c|c|c|c|c|c|c|}
\hline & \multicolumn{2}{|c|}{ E. coli ESBL-positive } & \multicolumn{2}{|c|}{ K. pneumoniae ESBL-positive } & \multicolumn{2}{|c|}{ H. influenzae BL positive } & \multicolumn{2}{|c|}{$P$. aeruginosa MDR } & \multicolumn{2}{|c|}{ A. baumannii MDR } & \multicolumn{2}{|c|}{ MRSA } \\
\hline & $\mathrm{n}$ & $\%$ & $\mathrm{n}$ & $\%$ & $\mathrm{n}$ & $\%$ & $\mathrm{n}$ & $\%$ & $\mathrm{n}$ & $\%$ & $\mathrm{n}$ & $\%$ \\
\hline 2013 & 46 & 14.9 & 75 & 36.1 & 39 & 25.3 & 33 & 13.6 & 11 & 12.2 & 84 & 28.0 \\
\hline 2014 & 43 & 15.6 & 85 & 40.7 & 27 & 18.9 & 21 & 9.8 & 10 & 13.5 & 76 & 27.9 \\
\hline 2015 & 47 & 16.8 & 71 & 36.4 & 36 & 25.7 & 11 & 5.3 & 7 & 9.1 & 50 & 18.3 \\
\hline 2016 & 20 & 19.8 & 34 & 43.6 & 20 & 35.1 & 3 & 4.0 & 7 & 24.1 & 24 & 23.5 \\
\hline
\end{tabular}

$B L$, $\beta$-lactamase, ESBL, extended-spectrum $\beta$-lactamase, $M D R$, multidrug-resistant, $M R S A$, methicillin-resistant $S$. aureus 
Table 3 Minimum inhibitory concentrations ( $\mathrm{MIC}_{90}$, MIC range $[\mathrm{mg} / \mathrm{L}]$ ) and antimicrobial susceptibility (\%S) and resistance (\%R) of Gram-negative isolates

\begin{tabular}{|c|c|c|c|c|c|c|c|c|}
\hline \multirow[t]{2}{*}{ Organism/ Antimicrobial } & \multicolumn{4}{|l|}{ 2004-2016 } & \multicolumn{4}{|l|}{ 2013-2016 } \\
\hline & $\mathrm{MIC}_{90}(\mathrm{mg} / \mathrm{L})$ & MIC Range (mg/L) & $\% S$ & $\% R$ & $\mathrm{MIC}_{90}(\mathrm{mg} / \mathrm{L})$ & MIC Range (mg/L) & $\% \mathrm{~S}$ & $\% R$ \\
\hline Enterobacter spp. & $N=3424$ & & & & $N=924$ & & & \\
\hline Amikacin & 4 & $\leq 0.5$ to $\geq 128$ & 96.9 & 1.1 & 4 & $\leq 0.5$ to $\geq 128$ & 98.4 & 0.8 \\
\hline Cefepime $^{a}$ & 16 & $\leq 0.5$ to $\geq 64$ & 69.5 & 15.8 & 32 & $\leq 0.5$ to $\geq 64$ & 67.1 & 19.8 \\
\hline Ceftriaxone & 64 & $\leq 0.06$ to $\geq 128$ & 50.9 & 45.6 & 64 & $\leq 0.06$ to 64 & 49.1 & 47.3 \\
\hline Levofloxacin $^{c}$ & $\leq 16$ & $\leq 0.008$ to $\geq 16$ & 71.5 & 25.0 & 8 & $\leq 0.008$ to $\geq 16$ & 75.8 & 19.7 \\
\hline Meropenem $(N=3113)^{b}$ & 0.25 & $\leq 0.06$ to $\geq 32$ & 99.2 & 0.3 & 0.25 & $\leq 0.06$ to $\geq 32$ & 99.4 & 0.2 \\
\hline Minocycline & 16 & $\leq 0.5$ to $\geq 32$ & - & - & 8 & $\leq 0.5$ to $\geq 32$ & - & - \\
\hline Pip-taz & 128 & $\leq 0.06$ to $\geq 256$ & 60.7 & 30.5 & 128 & $\leq 0.06$ to $\geq 256$ & 64.7 & 25.6 \\
\hline Tigecycline & 2 & 0.06 to 16 & 86.3 & 5.2 & 2 & 0.06 to 16 & 89.5 & 3.5 \\
\hline E. coli & $N=3527$ & & & & $N=965$ & & & \\
\hline Amikacin & 4 & $\leq 0.5$ to $\geq 128$ & 98.1 & 0.5 & 4 & $\leq 0.5$ to $\geq 128$ & 98.4 & 0.2 \\
\hline Amox-clav & 32 & 0.25 to $\geq 64$ & 72.1 & 27.9 & 16 & 0.5 to $\geq 64$ & 75.1 & 24.9 \\
\hline Ampicillin & $\geq 64$ & $\leq 0.5$ to $\geq 64$ & 37.9 & 62.1 & $\geq 64$ & $\leq 0.5$ to $\geq 64$ & 38.5 & 61.5 \\
\hline Cefepime $^{a}$ & 8 & $\leq 0.5$ to $\geq 64$ & 82.5 & 12.4 & 16 & $\leq 0.5$ to $\geq 64$ & 80.7 & 13.8 \\
\hline Ceftriaxone $^{a}$ & 64 & $\leq 0.06$ to $\geq 128$ & 82.6 & 16.8 & 64 & $\leq 0.06$ to 64 & 81.3 & 18.4 \\
\hline Levofloxacin & $\geq 16$ & $\leq 0.008$ to $\geq 16$ & 78.5 & 20.2 & 8 & $\leq 0.008$ to $\geq 16$ & 79.6 & 19.4 \\
\hline Meropenem $(N=3203)^{b}$ & $\leq 0.06$ & $\leq 0.06$ to 8 & 99.9 & 0.0 & $\leq 0.06$ & $\leq 0.06$ to 8 & 99.9 & 0.0 \\
\hline Minocycline & 8 & $\leq 0.5$ to $\geq 32$ & - & - & 8 & $\leq 0.5$ to $\geq 32$ & - & - \\
\hline Pip-taz & 16 & $\leq 0.06$ to $\geq 256$ & 89.6 & 7.2 & 8 & $\leq 0.06$ to $\geq 256$ & 91.6 & 6.2 \\
\hline Tigecycline & 0.5 & $\leq 0.008$ to 16 & 99.4 & 0.1 & 0.25 & 0.03 to 16 & 99.5 & 0.1 \\
\hline E. coli, ESBL & $N=489$ & & & & $N=156$ & & & \\
\hline Amikacin & 8 & $\leq 0.5$ to $\geq 128$ & 92.6 & 2.2 & 8 & 1 to $\geq 128$ & 95.5 & 0.6 \\
\hline Amox-clav ${ }^{c}$ & 32 & 2 to $\geq 64$ & 45.8 & 54.2 & 16 & 2 to $\geq 64$ & 59.0 & 41.0 \\
\hline Ampicillin & $\geq 64$ & 32 to $\geq 64$ & 0.0 & 100 & $\geq 64$ & 64 to $\geq 64$ & 0.0 & 100 \\
\hline Cefepime & $\geq 64$ & $\leq 0.5$ to $\geq 64$ & 3.9 & 78.3 & $\geq 64$ & 1 to $\geq 64$ & 3.2 & 79.5 \\
\hline Ceftriaxone & $\geq 128$ & 2 to $\geq 128$ & 0.0 & 99.2 & 64 & 4 to 64 & 0.0 & 100 \\
\hline Levofloxacin & $\geq 16$ & $\leq 0.008$ to $\geq 16$ & 37.8 & 59.7 & $\geq 16$ & 0.015 to $\geq 16$ & 42.3 & 55.1 \\
\hline Meropenem $(N=472)^{b}$ & $\leq 0.06$ & $\leq 0.06$ to 2 & 100 & 0.0 & $\leq 0.06$ & $\leq 0.06$ to 1 & 100 & 0.0 \\
\hline Minocycline & 16 & $\leq 0.5$ to $\geq 32$ & - & - & 16 & $\leq 0.5$ to $\geq 32$ & - & - \\
\hline Pip-taz & 32 & 0.25 to $\geq 256$ & 78.3 & 12.7 & 16 & 0.25 to $\geq 256$ & 88.5 & 3.8 \\
\hline Tigecycline & 0.5 & 0.03 to 2 & 99.2 & 0.0 & 0.25 & 0.03 to 2 & 99.4 & 0.0 \\
\hline H. influenzae & $N=1786$ & & & & $N=494$ & & & \\
\hline Amikacin & 8 & $\leq 0.5$ to 64 & - & - & 8 & $\leq 0.5$ to 16 & - & - \\
\hline Amox-clav & 1 & $\leq 0.12$ to 16 & 99.2 & 0.8 & 1 & $\leq 0.12$ to 4 & 99.0 & 1.0 \\
\hline Ampicillin & 32 & $\leq 0.5$ to $\geq 64$ & 75.4 & 24.6 & 32 & $\leq 0.5$ to $\geq 64$ & 74.1 & 25.9 \\
\hline Cefepime & $\leq 0.5$ & $\leq 0.5$ to 2 & - & - & $\leq 0.5$ & $\leq 0.5$ to 2 & - & - \\
\hline Ceftriaxone & $\leq 0.06$ & $\leq 0.06$ to 4 & 98.6 & 1.4 & $\leq 0.06$ & $\leq 0.06$ to 2 & 99.4 & 0.4 \\
\hline Levofloxacin & 0.015 & $\leq 0.008$ to 8 & 98.4 & 1.6 & 0.015 & $\leq 0.008$ to 8 & 98.6 & 1.4 \\
\hline Meropenem $(N=1629)^{b}$ & 0.12 & $\leq 0.06$ to 0.5 & 100 & 0.0 & 0.12 & $\leq 0.06$ to 0.5 & 100 & 0.0 \\
\hline Minocycline & 1 & $\leq 0.5$ to 16 & 91.8 & 1.6 & 1 & $\leq 0.5$ to 4 & 93.1 & 0.8 \\
\hline Pip-taz & $\leq 0.06$ & $\leq 0.06$ to 0.5 & - & - & $\leq 0.06$ & $\leq 0.06$ to 0.5 & - & - \\
\hline Tigecycline & 0.25 & $\leq 0.008$ to 4 & - & - & 0.25 & $\leq 0.008$ to 0.25 & - & - \\
\hline
\end{tabular}


Table 3 Minimum inhibitory concentrations ( $\mathrm{MIC}_{90}, \mathrm{MIC}$ range $[\mathrm{mg} / \mathrm{L}]$ ) and antimicrobial susceptibility (\%S) and resistance (\%R) of Gram-negative isolates (Continued)

\begin{tabular}{|c|c|c|c|c|c|c|c|c|}
\hline \multirow[t]{2}{*}{ Organism/ Antimicrobial } & \multicolumn{4}{|l|}{ 2004-2016 } & \multicolumn{4}{|l|}{ 2013-2016 } \\
\hline & $\mathrm{MIC}_{90}(\mathrm{mg} / \mathrm{L})$ & MIC Range (mg/L) & $\% S$ & $\% R$ & $\mathrm{MIC}_{90}(\mathrm{mg} / \mathrm{L})$ & MIC Range (mg/L) & $\% S$ & $\% R$ \\
\hline H. influenzae, BL Positive & $N=410$ & & & & $N=122$ & & & \\
\hline Amikacin & 8 & $\leq 0.5$ to 32 & - & - & 8 & $\leq 0.5$ to 16 & - & - \\
\hline Amox-clav & 2 & $\leq 0.12$ to 16 & 97.3 & 2.7 & 2 & $\leq 0.12$ to 4 & 95.9 & 4.1 \\
\hline Ampicillin & $\geq 64$ & $\leq 0.5$ to $\geq 64$ & 0.5 & 99.5 & $\geq 64$ & $\leq 0.5$ to $\geq 64$ & 0.8 & 99.2 \\
\hline Cefepime & $\leq 0.5$ & $\leq 0.5$ to 2 & - & - & $\leq 0.5$ & $\leq 0.5$ to 2 & - & - \\
\hline Ceftriaxone & $\leq 0.06$ & $\leq 0.06$ to 4 & 97.8 & 2.2 & $\leq 0.06$ & $\leq 0.06$ to 2 & 99.2 & 0.8 \\
\hline Levofloxacin & 0.03 & $\leq 0.008$ to 1 & 97.8 & 2.2 & 0.015 & $\leq 0.008$ to 0.5 & 97.5 & 2.5 \\
\hline Meropenem $(N=378)^{\mathrm{b}}$ & 0.12 & $\leq 0.06$ to 0.5 & 100 & 0.0 & 0.12 & $\leq 0.06$ to 0.5 & 100 & 0.0 \\
\hline Minocycline & 1 & $\leq 0.5$ to 16 & 93.2 & 0.5 & 1 & $\leq 0.5$ to 2 & 93.4 & 0.0 \\
\hline Pip-taz & $\leq 0.06$ & $\leq 0.06$ to 0.5 & - & - & $\leq 0.06$ & $\leq 0.06$ to 0.5 & - & - \\
\hline Tigecycline & 0.25 & $\leq 0.008$ to 0.5 & - & - & 0.25 & $\leq 0.008$ to 0.25 & - & - \\
\hline K. oxytoca & $N=975$ & & & & $N=225$ & & & \\
\hline Amikacin & 4 & $\leq 0.5$ to $\geq 128$ & 98.9 & 0.4 & 4 & $\leq 0.5$ to 16 & 99.1 & 0.0 \\
\hline Amox-clav & 32 & 0.25 to $\geq 64$ & 79.8 & 20.2 & 16 & 0.25 to $\geq 64$ & 82.2 & 17.8 \\
\hline Cefepime & 2 & $\leq 0.5$ to $\geq 64$ & 88.4 & 3.9 & 2 & $\leq 0.5$ to $\geq 64$ & 88.4 & 4.9 \\
\hline Ceftriaxone & 8 & $\leq 0.06$ to $\geq 128$ & 83.2 & 14.5 & 4 & $\leq 0.06$ to 64 & 85.8 & 12.0 \\
\hline Levofloxacin & 1 & $\leq 0.008$ to $\geq 16$ & 89.5 & 8.4 & 0.25 & 0.015 to $\geq 16$ & 94.2 & 4.4 \\
\hline Meropenem $(N=872)^{b}$ & $\leq 0.06$ & $\leq 0.06$ to $\geq 32$ & 99.8 & 0.1 & $\leq 0.06$ & $\leq 0.06$ to 1 & 100 & 0.0 \\
\hline Minocycline & 4 & $\leq 0.5$ to $\geq 32$ & - & - & 2 & $\leq 0.5$ to 16 & - & - \\
\hline Pip-taz & $\geq 256$ & $\leq 0.06$ to $\geq 256$ & 84.0 & 15.1 & 64 & 0.25 to $\geq 256$ & 87.6 & 11.6 \\
\hline Tigecycline & 1 & 0.015 to 8 & 95.8 & 1.0 & 0.5 & 0.12 to 4 & 96.9 & 0.9 \\
\hline K. pneumoniae & $N=2398$ & & & & $N=690$ & & & \\
\hline Amikacin & 4 & $\leq 0.5$ to $\geq 128$ & 96.5 & 1.5 & 4 & $\leq 0.5$ to $\geq 128$ & 96.8 & 1.7 \\
\hline Amox-clav ${ }^{a}$ & 32 & 0.5 to $\geq 64$ & 68.6 & 31.4 & 32 & 1 to $\geq 64$ & 61.4 & 38.6 \\
\hline Cefepime $^{a}$ & $\geq 64$ & $\leq 0.5$ to $\geq 64$ & 72.1 & 23.4 & $\geq 64$ & $\leq 0.5$ to $\geq 64$ & 59.9 & 35.5 \\
\hline Ceftriaxone $^{a}$ & 64 & $\leq 0.06$ to $\geq 128$ & 70.3 & 28.7 & 64 & $\leq 0.06$ to 64 & 58.4 & 41.4 \\
\hline Levofloxacin $^{a}$ & 8 & $\leq 0.008$ to $\geq 16$ & 76.1 & 20.0 & 8 & 0.015 to $\geq 16$ & 72.3 & 23.2 \\
\hline Meropenem $^{\mathrm{a}}(N=2186)^{\mathrm{b}}$ & 0.12 & $\leq 0.06$ to $\geq 32$ & 99.4 & 0.4 & 0.12 & $\leq 0.06$ to $\geq 32$ & 98.8 & 1.0 \\
\hline Minocycline & 16 & $\leq 0.5$ to $\geq 32$ & - & - & 16 & $\leq 0.5$ to $\geq 32$ & - & - \\
\hline Pip-taz & 64 & 0.12 to $\geq 256$ & 81.9 & 13.1 & 32 & 0.12 to $\geq 256$ & 84.1 & 10.3 \\
\hline Tigecycline $^{a}$ & 2 & 0.06 to 16 & 87.4 & 5.0 & 2 & 0.06 to 8 & 86.2 & 7.0 \\
\hline K. pneumoniae, ESBL & $N=622$ & & & & $N=265$ & & & \\
\hline Amikacin & 8 & $\leq 0.5$ to $\geq 128$ & 90.0 & 4.2 & 8 & $\leq 0.5$ to $\geq 128$ & 94.7 & 3.8 \\
\hline Amox-clav & 32 & 1 to $\geq 64$ & 19.0 & 81.0 & 32 & 1 to $\geq 64$ & 20.8 & 79.2 \\
\hline Cefepime $^{a}$ & $\geq 64$ & $\leq 0.5$ to $\geq 64$ & 5.0 & 85.0 & $\geq 64$ & $\leq 0.5$ to $\geq 64$ & 3.8 & 86.8 \\
\hline Ceftriaxone & $\geq 128$ & $\leq 0.06$ to $\geq 128$ & 1.3 & 98.4 & 64 & $\leq 0.06$ to 64 & 1.1 & 98.9 \\
\hline Levofloxacin ${ }^{c}$ & $\geq 16$ & 0.03 to $\geq 16$ & 30.2 & 61.1 & $\geq 16$ & 0.03 to $\geq 16$ & 38.9 & 50.9 \\
\hline Meropenem $(N=603)^{b}$ & 0.12 & $\leq 0.06$ to $\geq 32$ & 99.0 & 0.3 & 0.12 & $\leq 0.06$ to 16 & 99.2 & 0.4 \\
\hline Minocycline & $\geq 32$ & $\leq 0.5$ to $\geq 32$ & - & - & $\geq 32$ & $\leq 0.5$ to $\geq 32$ & - & - \\
\hline Pip-taz $^{c}$ & $\geq 256$ & 0.25 to $\geq 256$ & 54.0 & 32.8 & 128 & 0.25 to $\geq 256$ & 68.7 & 18.5 \\
\hline Tigecycline & 2 & 0.12 to 8 & 79.4 & 7.2 & 2 & 0.12 to 8 & 80.0 & 7.9 \\
\hline S. marcescens & $N=1345$ & & & & $N=360$ & & & \\
\hline
\end{tabular}


Table 3 Minimum inhibitory concentrations ( $\mathrm{MIC}_{90}, \mathrm{MIC}$ range $[\mathrm{mg} / \mathrm{L}]$ ) and antimicrobial susceptibility (\%S) and resistance (\%R) of Gram-negative isolates (Continued)

\begin{tabular}{|c|c|c|c|c|c|c|c|c|}
\hline \multirow[t]{2}{*}{ Organism/ Antimicrobial } & \multicolumn{4}{|l|}{ 2004-2016 } & \multicolumn{4}{|l|}{ 2013-2016 } \\
\hline & $\mathrm{MIC}_{90}(\mathrm{mg} / \mathrm{L})$ & MIC Range (mg/L) & $\% \mathrm{~S}$ & $\% \mathrm{R}$ & $\mathrm{MIC}_{90}(\mathrm{mg} / \mathrm{L})$ & MIC Range (mg/L) & $\% \mathrm{~S}$ & $\% \mathrm{R}$ \\
\hline Amikacin & 4 & $\leq 0.5$ to $\geq 128$ & 97.3 & 1.1 & 4 & $\leq 0.5$ to 64 & 98.3 & 0.6 \\
\hline Cefepime & $\leq 0.5$ & $\leq 0.5$ to $\geq 64$ & 94.5 & 2.2 & $\leq 0.5$ & $\leq 0.5$ to $\geq 32$ & 94.7 & 1.9 \\
\hline Ceftriaxone & 8 & $\leq 0.06$ to $\geq 128$ & 82.2 & 13.8 & 2 & $\leq 0.06$ to 64 & 86.9 & 8.9 \\
\hline Levofloxacin $^{c}$ & 2 & $\leq 0.008$ to $\geq 16$ & 84.2 & 10.6 & 1 & $\leq 0.008$ to $\geq 16$ & 89.4 & 5.6 \\
\hline Meropenem $(N=1227)^{\mathrm{b}}$ & 0.12 & $\leq 0.06$ to $\geq 32$ & 99.1 & 0.1 & 0.12 & $\leq 0.06$ to 2 & 100 & 0.0 \\
\hline Minocycline & 8 & $\leq 0.5$ to $\geq 32$ & - & - & 4 & $\leq 0.5$ to $\geq 32$ & - & - \\
\hline Pip-taz & 16 & $\leq 0.06$ to $\geq 256$ & 89.9 & 6.2 & 8 & $\leq 0.06$ to 128 & 93.9 & 3.3 \\
\hline Tigecycline & 2 & 0.015 to 8 & 80.7 & 2.6 & 2 & 0.03 to 4 & 80.3 & 1.1 \\
\hline A. baumannii & $N=1496$ & & & & $N=270$ & & & \\
\hline Amikacin & $\geq 128$ & $\leq 0.5$ to $\geq 128$ & 74.9 & 19.9 & $\geq 128$ & 1 to $\geq 128$ & 73.7 & 20.4 \\
\hline Cefepime & 32 & $\leq 0.5$ to $\geq 64$ & - & - & $\geq 64$ & $\leq 0.5$ to $\geq 64$ & - & - \\
\hline Ceftazidime $(N=1488)$ & $\geq 64$ & $\leq 1$ to $\geq 64$ & - & - & 32 & $\leq 1$ to 32 & - & - \\
\hline Ceftriaxone & $\geq 128$ & $\leq 0.06$ to $\geq 128$ & - & - & 64 & 2 to 64 & - & - \\
\hline Levofloxacin & $\geq 16$ & $\leq 0.008$ to $\geq 16$ & 54.5 & 43.2 & $\geq 16$ & $\leq 0.008$ to $\geq 16$ & 56.7 & 42.6 \\
\hline Meropenem $^{a}(N=1326)^{b}$ & $\geq 32$ & $\leq 0.06$ to $\geq 32$ & 81.0 & 11.8 & $\geq 32$ & 0.12 to $\geq 32$ & 74.1 & 20 \\
\hline Minocycline & 8 & $\leq 0.5$ to $\geq 32$ & - & - & 8 & $\leq 0.5$ to $\geq 32$ & - & - \\
\hline Pip-taz & $\geq 256$ & $\leq 0.06$ to $\geq 256$ & - & - & $\geq 256$ & $\leq 0.06$ to $\geq 256$ & - & - \\
\hline Tigecycline & 1 & $\leq 0.008$ to 8 & - & - & 1 & 0.03 to 2 & - & - \\
\hline A. baumannii MDR & $N=93$ & & & & $N=35$ & & & \\
\hline Amikacin & $\geq 128$ & 32 to $\geq 128$ & 0.0 & 100 & $\geq 128$ & 32 to $\geq 128$ & 0.0 & 100 \\
\hline Cefepime & $\geq 64$ & 8 to $\geq 64$ & - & - & $\geq 64$ & 8 to $\geq 64$ & - & - \\
\hline Ceftazidime $(N=92)$ & $\geq 64$ & $\leq 1$ to $\geq 64$ & - & - & 32 & 2 to 32 & - & - \\
\hline Ceftriaxone & $\geq 128$ & 64 to $\geq 128$ & - & - & 64 & 64 to 64 & - & - \\
\hline Levofloxacin & $\geq 16$ & 2 to $\geq 16$ & 0.0 & 100 & $\geq 16$ & 2 to $\geq 16$ & 0.0 & 100 \\
\hline Meropenem $(N=92)^{b}$ & $\geq 32$ & 16 to $\geq 32$ & 0.0 & 100 & $\geq 32$ & 16 to $\geq 32$ & 0.0 & 100 \\
\hline Minocycline & 16 & $\leq 0.5$ to $\geq 32$ & - & - & 16 & $\leq 0.5$ to $\geq 32$ & - & - \\
\hline Pip-taz & $\geq 256$ & $\leq 0.06$ to $\geq 256$ & - & - & $\geq 256$ & 64 to $\geq 256$ & - & - \\
\hline Tigecycline & 4 & 0.12 to 4 & - & - & 2 & 0.25 to 2 & - & - \\
\hline P. aeruginosa & $N=2734$ & & & & $N=738$ & & & \\
\hline Amikacin & 16 & $\leq 0.5$ to $\geq 128$ & 88.5 & 6.9 & 8 & $\leq 0.5$ to $\geq 128$ & 91.1 & 5.1 \\
\hline Cefepime & 32 & $\leq 0.5$ to $\geq 64$ & 77.8 & 22.2 & 16 & $\leq 0.5$ to $\geq 64$ & 79.8 & 20.2 \\
\hline Ceftazidime ( $N=2730)$ & 32 & $\leq 1$ to $\geq 64$ & 77.2 & 22.8 & 32 & $\leq 1$ to 32 & 80.2 & 19.8 \\
\hline Levofloxacin ${ }^{c}$ & $\geq 16$ & $\leq 0.008$ to $\geq 16$ & 60.6 & 39.4 & $\geq 16$ & 0.015 to $\geq 16$ & 65.7 & 34.3 \\
\hline Meropenem $(N=2474)$ & 8 & $\leq 0.06$ to $\geq 32$ & 74.6 & 8.7 & 16 & $\leq 0.06$ to $\geq 32$ & 75.2 & 10.0 \\
\hline Pip-taz ${ }^{c}$ & 128 & $\leq 0.06$ to $\geq 256$ & 74.4 & 25.6 & 128 & $\leq 0.06$ to $\geq 256$ & 78.7 & 21.3 \\
\hline Tigecycline & 16 & $\leq 0.008$ to $\geq 32$ & - & - & 16 & 0.12 to 16 & - & - \\
\hline P. aeruginosa MDR & $N=271$ & & & & $N=68$ & & & \\
\hline Amikacin & $\geq 128$ & 1 to $\geq 128$ & 31.4 & 58.3 & $\geq 128$ & 2 to $\geq 128$ & 38.2 & 50.0 \\
\hline Cefepime & $\geq 64$ & 2 to $\geq 64$ & 14.0 & 86.0 & $\geq 64$ & 4 to $\geq 64$ & 8.8 & 91.2 \\
\hline Ceftazidime & $\geq 64$ & 2 to $\geq 64$ & 21.4 & 78.6 & 32 & 4 to 32 & 23.5 & 76.5 \\
\hline Levofloxacin & $\geq 16$ & 0.5 to $\geq 16$ & 1.5 & 98.5 & $\geq 16$ & 2 to $\geq 16$ & 0.0 & 100 \\
\hline Meropenem $^{\mathrm{a}}(N=258)^{\mathrm{b}}$ & $\geq 32$ & $\leq 0.06$ to $\geq 32$ & 17.8 & 66.7 & $\geq 32$ & 0.25 to $\geq 32$ & 11.8 & 82.4 \\
\hline
\end{tabular}


Table 3 Minimum inhibitory concentrations ( $\mathrm{MIC}_{90}, \mathrm{MIC}$ range $[\mathrm{mg} / \mathrm{L}]$ ) and antimicrobial susceptibility (\%S) and resistance (\%R) of Gram-negative isolates (Continued)

\begin{tabular}{|c|c|c|c|c|c|c|c|c|}
\hline \multirow[t]{2}{*}{ Organism/ Antimicrobial } & \multicolumn{4}{|l|}{ 2004-2016 } & \multicolumn{4}{|l|}{ 2013-2016 } \\
\hline & $\mathrm{MIC}_{90}(\mathrm{mg} / \mathrm{L})$ & MIC Range (mg/L) & $\% \mathrm{~S}$ & $\% \mathrm{R}$ & $\mathrm{MIC}_{90}(\mathrm{mg} / \mathrm{L})$ & MIC Range (mg/L) & $\% \mathrm{~S}$ & $\% R$ \\
\hline$\overline{\text { Pip-taz }^{c}}$ & $\geq 256$ & 0.5 to $\geq 256$ & 14.0 & 86.0 & $\geq 256$ & 1 to $\geq 256$ & 20.6 & 79.4 \\
\hline Tigecycline & $\geq 32$ & 1 to $\geq 32$ & - & - & 16 & 2 to 16 & - & - \\
\hline
\end{tabular}

- indicates no susceptibility breakpoints are available for this agent

a indicates statistically significant decrease in susceptibility $(p<0.01)$ from 2004 to 2016

${ }^{b}$ Meropenem was introduced to the testing panel in 2006, replacing imipenem; N values of activity against organisms collected from 2006 to 2016 are given c indicates statistically significant increase in susceptibility $(p<0.01)$ from 2004 to 2016

Amox-clav, amoxicillin-clavulanic acid, $B L, \beta$-lactamase, ESBL, extended-spectrum $\beta$-lactamase, MDR, multidrug-resistant, $M I C$, minimum inhibitory concentration, $M I C_{90}$, minimum inhibitory concentration required to inhibit growth of $90 \%$ of isolates $(\mathrm{mg} / \mathrm{L})$, Pip-taz, piperacillin-tazobactam, $R$, resistant, $\mathrm{S}$, susceptible

\section{H. influenzae}

H. influenzae isolates $(N=1786)$, including $\beta$-lactamase positive isolates $(N=410,23.0 \%)$ collected between 2004 to 2016 (Table 3) were susceptible (>91.0\%) to agents in the T.E.S.T. panel with a breakpoint, with the exception of ampicillin, to which $75.4 \%$ of all $H$. influenzae isolates and $0.5 \%$ of $\beta$-lactamase positive isolates were susceptible.

\section{Klebsiella spp}

A total of $975 K$. oxytoca isolates were collected during the study, and susceptibilities were highest to meropenem $(N=872,99.8 \%)$, amikacin (98.9\%) and tigecycline (95.8\%). Over $80 \%$ of isolates were susceptible to cefepime, ceftriaxone, levofloxacin and piperacillin-tazobactam, and $79.8 \%$ of isolates were susceptible to amoxicillin-clavulanate.

Susceptibility of $K$. pneumoniae isolates collected between 2004 to $2016(N=2398)$ was highest to meropenem $(N=2186,99.4 \%)$, amikacin $(96.5 \%)$ and tigecycline $(87.4 \%)$ (Table 3$)$. There was a significant $(p<0.0001) \mathrm{de}-$ cline in susceptibilities to amoxicillin-clavulanate from $85.1 \%$ in 2004 to $46.2 \%$ in 2016 , cefepime $(95.5 \%$ in 2004 to $48.7 \%$ in 2016 ), ceftriaxone (91.0\% in 2004 to $47.4 \%$ in 2016), levofloxacin ( $92.5 \%$ in 2004 to $66.7 \%$ in 2016) and meropenem (100\% in 2004 to $92.3 \%$ in 2016 ).

The proportion of $K$. pneumoniae isolates identified as ESBL-positive between 2004 and $2016(N=622)$ was highest during 2016 (43.6\%) (Table 2), an increase from 36.1\% in 2013 and from 7.5\% in 2004. Susceptibility was highest to meropenem $(N=603,99.0 \%)$, amikacin $(90.0 \%)$ and tigecycline (79.4\%). Six K. pneumoniae isolates collected from one centre in 2016 were resistant to meropenem and these isolates were not ESBL-producers. Very few ESBL-positive isolates were susceptible to cefepime (5.0\%) and ceftriaxone (1.3\%) during the study, although susceptibility to levofloxacin improved to its highest level in 2016 (47.1\%), and the susceptibility to piperacillin-tazobactam was $79.4 \%$ in 2016 , a similar value compared with $80.0 \%$ susceptibility in 2004 .

\section{S. marcescens}

Between 2004 and 2016, 1345 isolates of S. marcescens were collected, and susceptibility was highest to meropenem $(N=1227,99.1 \%)$, amikacin $(97.3 \%)$ and cefepime (94.5\%).

\section{A. baumannii}

Few agents showed in vitro activity against $A$. baumannii isolates $(N=1496)$ (Table 3$)$, with tigecycline and minocycline the two agents with relatively low $\mathrm{MIC}_{90}$ values (1 $\mathrm{mg} / \mathrm{L}$ and $8 \mathrm{mg} / \mathrm{L}$ respectively); clinical breakpoints for these two agents are not available. Susceptibility to meropenem $(N=1326)$ was $81.0 \%$ and to amikacin $74.9 \%$. There was a significant decrease $(p<0.0001)$ in the proportion of isolates that were susceptible to meropenem, from $84.8 \%$ in 2006 to $65.5 \%$ in 2016 . None of the $A$. baumannii MDR isolates was susceptible to amikacin, levofloxacin (both $N=93$ ) and meropenem $(N=92)$, the three agents with breakpoints. Antimicrobial activity of tigecycline against $A$. baumannii MDR isolates appeared reduced $\left(\mathrm{MIC}_{90} 4 \mathrm{mg} / \mathrm{L}\right)$ compared with all $A$. baumannii isolates. The proportion of $A$. baumannii MDR isolates increased from zero in 2004 to a high of $24.1 \%$ in 2016 (Table 2).

\section{$P$. aeruginosa}

A total of $2734 P$. aeruginosa isolates were collected during the study and susceptibility to antimicrobial agents was stable. Susceptibility was $88.5 \%$ to amikacin, whilst $77.8 \%$ of isolates were susceptible to cefepime, $77.2 \%$ to ceftazidime, $74.6 \%$ to meropenem and $74.4 \%$ to piperacillin-tazobactam. The proportion of $P$. aeruginosa isolates $(N=271)$ that were identified as MDR declined during the study from a high of $13.6 \%$ in 2013 to $4.0 \%$ in 2016 , and susceptibility of these isolates was highest to amikacin (31.4\%).

\section{Discussion}

This report is an update to data previously presented by Cattoir and Dowzicky [17] for France, and includes data from isolates that were collected between 2004 and 2016. Data presented by Cattoir and Dowzicky that were based on isolates collected in France from 2004 to 2012 are included in the dataset we describe in this update. 
The proportion of isolates identified as MRSA in our study was stable between 2004 and 2016, and averaged $27.7 \%$ compared with an average of $28.3 \%$ between 2004 and 2012 [17]. During the last four years of our study, there appeared to be a slight decline in MRSA rates from $28.0 \%$ to $23.5 \%$. Rates of MRSA in France were reported to be decreasing from 2003 to 2010 according to data from the RAISIN network published in 2013 by Carbonne et al. [2], and more recently the ECDC surveillance report identified an MRSA rate in France of $17.1 \%$ of invasive $S$. aureus isolates in 2013, $17.4 \%$ in $2014,15.7 \%$ in 2015 and $13.8 \%$ in 2016 [3]. The use of control measures including isolation of patients with MRSA, the use of alcohol-based hand-rub, and screening of high-risk patients [9], have resulted in improved control of MRSA transmission in French hospitals [9, 22]. Consequently the proportion of $S$. aureus isolates identified as MRSA in France is showing a downward trend, and similar trends have been observed in Germany and the UK by the ECDC, which reported MRSA rates in 2016 of 10.3 and $6.7 \%$, respectively [3]. Much higher MRSA rates have been reported in France's neighbouring countries of Spain (25.8\% in 2016) and Italy (33.6\% in 2016) [3].

Susceptibilities of $S$. aureus isolates collected in our study were stable to tigecycline, vancomycin, linezolid and minocycline, including MRSA isolates, which showed susceptibility rates between 2013 and 2016 of $100 \%$ to tigecycline, vancomycin and linezolid and $95.3 \%$ to minocycline. The same values were reported by Cattoir and Dowzicky [17] for MRSA isolates collected between 2004 and $2012(N=631)$ for tigecycline, vancomycin and linezolid, with minocycline susceptibility similar at $93.5 \%$. MRSA isolates collected in our study between 2013 to 2016 did not show any meaningful improvement in in vitro susceptibility to levofloxacin (17.5\%) compared with 2004 to 2012 (13.2\%) [17]. Beyond these favourable data, the spread of MRSA strains exhibiting a vancomycin MIC superior to $1 \mathrm{mg} / \mathrm{L}$ should be carefully monitored, according to their putative role in clinical therapeutic failure and additional associated resistance [23].

Susceptibility to vancomycin amongst Gram-positive isolates was $100 \%$ amongst S. aureus, S. agalactiae and S. pneumoniae, including resistant phenotypes. The proportion of Enterococcus spp. that were identified as vancomycin-resistant isolates from 2004 to 2012 by Cattoir and Dowzicky [17] was low (E. faecalis VRE 0.7\%, E. faecium VRE 5.4\%) and we report a similar observation after a further four years of study (2004 to 2016: E. faecalis VRE 0.8\%; E. faecium VRE 5.6\%).

There was a considerable reduction in the susceptibility of penicillin-resistant $S$. pneumoniae isolates to macrolides compared with all S. pneumoniae isolates in our study. However, susceptibility of penicillin-resistant
S. pneumoniae was appreciably higher to erythromycin amongst isolates that were collected in our study between 2013 and 2016 (38.5\%), compared with 19.4\% susceptibility amongst isolates collected between 2004 and 2012 and reported by Cattoir and Dowzicky [17].

In our study, the proportion of ESBL-producers among E. coli (16.2\%) between 2013 and 2016 represented a small increase compared with the 2004 to 2012 period reported by Cattoir and Dowzicky (12.0\%) [17]. A study in France by Carbonne et al. on behalf of the RAISIN network reported a threefold increase in $E$. coli ESBL-producers identified from isolates collected from patients in participating healthcare facilities between 2003 and 2010 [2]. The increasing prevalence of ESBL-positive Enterobacteriaceae reported in healthcare settings is compounded by an increasingly frequent distribution in community settings. A recent study investigating risk factors of $E$. coli ST131 in children in the community found a doubling of ESBL-positive Enterobacteriaceae between 2010 and 2015 that was mainly attributed to the E. coli ST131 clonal group [24]. The spread of ESBL-positive Enterobacteriaceae in France appears to be due to CTX-M-type enzymes encoded in plasmids playing a major role, with three ESBLs (CTX-M-15, CTX-M-1, CTX-M-14) accounting for $>75 \%$ of isolates in a recent study of 200 clinical ESBL-positive samples collected from 18 French hospitals [4].

In our study, the in vitro susceptibility of tigecycline (99.5\%), amikacin (98.4\%) and meropenem (99.9\%) observed against all E. coli isolates between 2013 and 2016 was retained among ESBL-positive isolates (99.4, 95.5 and $100 \%$, respectively), and was similar to values for ESBL-positive E. coli reported by Cattoir and Dowzicky for the period 2004 to 2012 (tigecycline, 98.9\%, amikacin 90.5\%, meropenem 100\%) [17]. Further comparison with the 2004 to 2012 dataset reveals an improvement in susceptibility of ESBL-positive E. coli isolates to amoxicillin-clavulanate (from 36.7\% between 2004 to 2012 to $59.0 \%$ between 2013 to 2016) and to piperacillin-tazobactam (from 72.4\% between 2004 to 2012 to $88.5 \%$ between 2013 and 2016). Susceptibility trends similar to those observed for E. coli isolates were observed amongst $K$. pneumoniae and ESBL-positive $K$. pneumoniae isolates for tigecycline, amikacin and meropenem. The sustained decline in susceptibility of $K$. pneumoniae to ceftriaxone during our study appears to be attributable to the increase in the proportion of ESBL-positive $K$. pneumoniae isolates that was observed as the study progressed, reaching its highest value of $43.6 \%$ in 2016 . The high prevalence of K. pneumoniae isolates with antibiotic resistance has also been reported by the ECDC, which observed that $28.9 \%$ of K. pneumonia isolates from France in 2016 were resistant to third-generation cephalosporins, and the majority of these were ESBL-positive [3]. 
A recent study of infections caused by carbapenemases that were notified by local healthcare facilities to the French Institute for Public Health in France between 2004 and 2011 reported a sharp increase in annual reported episodes of CPE from three or less from 2004 to 2008, then six in 2009, 26 in 2010 and 13 in 2011 [5]. A total of 53 episodes were reported in all, and 42 were associated with cross-border transfers, suggesting that CPE were not endemic in France by 2011. Most CPE were mainly $K$. pneumoniae or E. coli, with the majority of carbapenemases identified as OXA-48 or a K. pneumoniae carbapenemase (KPC). A further study, by Dortet et al. [25], identified a more than twofold increase in Enterobacteriaceae isolates with decreased susceptibility to carbapenems that were received at the French Associated National Reference Centre from 2012 to 2014. The predominant carbapenemases identified in their study were OXA-48 variants. Despite apparent increases in the numbers of carbapenemases reported in France, the proportion of Enterobacteriaceae isolates with non-susceptibility to carbapenems would appear to remain very low; a rate of $0.63 \%$ was identified amongst 133,244 clinical isolates collected from 71 laboratories across France by Robert et al. [26], and $0.4 \%$ of K. pneumoniae isolates collected across France as part of the ECDC antimicrobial surveillance in Europe were identified as carbapenemase-resistant [3]. These findings are consistent with our study, in which almost all ESBL-positive isolates were susceptible to meropenem.

The proportion of $A$. baumannii isolates identified as MDR between 2004 and 2012 by Cattoir and Dowzicky was $4.7 \%$ [17], and although the proportion of MDR isolates increased considerably during the four further years of our study, increasing to $24.1 \%$ in 2016 , the number of MDR isolates $(n=7)$ was low. A recent study in France of A. baumannii carbapenem non-susceptible isolates noted that the proportion of carbapenem non-susceptible strains amongst all $A$. baumannii isolates was low during 2001 and 2002, increased to $2.6 \%$ in 2003 and remained at $\leq 3.2 \%$ until 2009 , when it increased to $5.0 \%$ of isolates or higher until the study concluded in 2011 [27]. The clinical threat presented by the increasing frequency of $A$. baumannii isolates that harbour carbapenemases is likely to be limited by the relatively low proportion of infections caused by $A$. baumannii, which were reported to account for just $0.02 \%$ of infections per 100 patients in French healthcare facilities in the 2012 French Point Prevalence Survey [28]. During our study, A. baumannii MDR isolates accounted for just $0.4 \%$ of all isolates collected between 2004 and 2016, suggesting that MDR A. baumannii is rare in France. Despite this, we report a notable fall in the in vitro susceptibility of MDR A. baumannii isolates to amikacin, levofloxacin and meropenem to the extent that none of the isolates was susceptible. Furthermore, the increase in the $\mathrm{MIC}_{90}$ value of tigecycline to $4 \mathrm{mg} / \mathrm{L}$ against MDR A. baumannii isolates from $1 \mathrm{mg} / \mathrm{L}$ against all $A$. baumannii isolates suggests a reduction in its antimicrobial activity, and underlines the paucity of effective antimicrobial agents that are available to physicians when treating infections caused by MDR A. baumannii.

Limitations of this study include a reduction in the number of centres in 2016 to four, which has the potential to magnify resistance rates should a single site experience a clonal outbreak or a resistant phenotype. There was one occurrence of this during 2016, when six ESBL-negative $K$. pneumoniae isolates from one centre were identified as resistant to meropenem. The source of one of these isolates was body fluids, and the remaining five were from faeces/stools. This outbreak was unlikely to significantly affect the antimicrobial susceptibility trends that we report, however there is the possibility of clonal outbreaks at a single site influencing the reported rates of resistant pathogens in our study. A further possible limitation might arise from the collection of isolates. The T.E.S.T. protocol specifies that each submitted isolate must be considered by the contributing centre to be the probable causative agent of an infection. Between 2004 and 2016, 36.4\% $(N=772)$ of isolates from GI sources originated from faeces/stool (1.1\% of the total number of isolates collected in the study), and it is conceivable that organisms identified from these isolates may not have been the probable causative agent of infection, a fact that has probably very slightly overestimated the resistance rates in Enterobacteriaceae. However, we would suggest that given the very low proportion of isolates obtained from this source, the overall trends we have observed in antimicrobial activity and rates of resistant phenotypes remain valid. Finally, although the report of global resistance rate is relevant, more accurate data according to the origin of the infection (i.e. community-associated or healthcare-associated) or the clinical context (e.g. bacteraemia, urinary tract infection, respiratory tract infection) should be of interest.

\section{Conclusions}

During this study, nearly all (> 90.0\%) Gram-positive isolates collected between 2004 and 2016 were susceptible in vitro to tigecycline, meropenem and linezolid, including MRSA and VRE phenotypes. Tigecycline and meropenem were also active in vitro against most Gram-negative isolates, including ESBL producers. The rates of MRSA and VRE we observed are stable, however there were notable increases in the rates of ESBL producers in E. coli and $K$. pneumoniae, accompanied by an increase in the proportion of $A$. baumannii isolates that were identified as MDR. These trends highlight the continued importance of surveillance studies for monitoring antimicrobial resistance and demonstrate the need for 
effective strategies to control the spread of resistant pathogens in hospital- and community-acquired infections in France.

\section{Abbreviations}

CIAls: Complicated intra-abdominal infections; CLSI: Clinical and Laboratory Standards Institute; CPE: Carbapenemase-producing Enterobacteriaceae; CSSTIs: Complicated skin and soft tissue infections; ECDC: European Centre for Disease Prevention and Control; ESBL: Extended-spectrum $\beta$-lactamase; EUCAST: European Committee on Antimicrobial Susceptibility Testing; Gl: Gastrointestinal; IHMA: International Health Management Associates; KPC: Klebsiella pneumonia carbapenemase; MDR: Multidrug-resistant; MIC: Minimum inhibitory concentration; $\mathrm{MIC}_{90}$ : MIC required to inhibit growth of 90\% of isolates; MRSA: Methicillin-resistant Staphylococcus aureus; RAISIN: French national healthcare-associated infection early warning, investigation and surveillance network [Réseau d'alerte, d'investigation et de surveillance des infections nosocomiales]; T.E.S.T.: Tigecycline Evaluation and Surveillance Trial; VRE: Vancomycin-resistant enterococci

\section{Acknowledgements}

The authors would like to thank all T.E.S.T. investigators and laboratories in France for their participation in the study and would also like to thank the staff at IHMA for their coordination of T.E.S.T.

\section{Funding}

T.E.S.T. is funded by Pfizer. Medical writing support was provided by Dr. Neera Hobson, Dr. Wendy Hartley and Mike Leedham, employees of Micron Research Ltd., Ely, UK, and was funded by Pfizer. Micron Research Ltd. also provided data management services which were funded by Pfizer.

\section{Availability of data and materials}

The datasets used and/or analysed during the current study are available from the corresponding author on reasonable request.

\section{Authors' contributions}

C-JS, J-WD, P-LW and MF-G all participated in data collection and interpretation as well as drafting and reviewing the manuscript. MJD was involved in the study design and participated in data interpretation and drafting and review of the manuscript. All authors read and approved the final manuscript.

\section{Ethics approval and consent to participate}

Not applicable.

\section{Competing interests}

C-J.S., J-W.D., P-L.W. and M.F-G have no competing interests relating to this paper. M.J.D. is an employee of Pfizer, Inc.

\section{Publisher's Note}

Springer Nature remains neutral with regard to jurisdictional claims in published maps and institutional affiliations.

\section{Author details}

${ }^{1}$ University Hospital Henri Mondor, 9400 Creteil, France. ${ }^{2}$ Caen University Hospital, 14033 Caen, Cedex 9, France. ${ }^{3}$ Pfizer Inc, Collegeville, PA, USA.

Received: 16 February 2018 Accepted: 21 May 2018

Published online: 30 May 2018

\section{References}

1. European Centre for Disease Prevention and Control (ECDC). Summary of the latest data on antibiotic consumption in EU: 2016. Available at: https:// ecdc.europa.eu/en/publications-data/summary-latest-data-antibioticconsumption-eu-2016. Accessed 12 Oct 2017.

2. Carbonne A, Arnaud I, Maugat S, Marty N, Dumartin C, Bertrand X, on behalf of the MDRB National Steering Group (BMR-Raisin), et al. National multidrug-resistant bacteria (MDRB) surveillance in France through the RAISIN network: a 9 year experience. J Antimicrob Chemother. 2013;68:954-9.

3. European Centre for Disease Prevention and Control. Surveillance of antimicrobial resistance in Europe 2016. Annual Report of the European
Antimicrobial Resistance Network (EARS-Net). Stockholm: ECDC; 2017. https://ecdc.europa.eu/en/publications-data/antimicrobial-resistancesurveillance-europe-2016. Accessed 05 Jan 2018.

4. Robin F, Beyrouthy R, Bonacorsi S, Aissa N, Bret L, Brieu N, et al. Inventory of extended-spectrum- $\beta$-lactamase-producing Enterobacteriaceae in France as assessed by a multicenter study. Antimicrob Agents Chemother. 2017;61:e01911-6.

5. Vaux S, Carbonne A, Thiolet JM, Jarlier V, Coignard B, RAISIN and Expert Laboratories Groups. Emergence of carbapenemase-producing Enterobacteriaceae in France, 2004 to 2011. Euro Surveill. 2011;16(22):19880.

6. Albiger B, Glasner C, Strueiens MJ, Monnet DL, the European Survey of Carbapenemase-Producing Enterobacteriaceae (EuSCAPE) working group. Carbapenemase-producing Enterobacteriaceae in Europe: assessment by national experts from 38 countries, May 2015. Euro Surveill. 2015;20(45):30062.

7. Lepelletier D, Berthelot P, Lucet JC, Fournier S, Jarlier V, Grandbastien B, et al. French recommendations for the prevention of 'emerging extensively drugresistant bacteria' (eXDR) cross-transmission. J Hosp Infect. 2015;90(3):186-95.

8. European Centre for Disease Prevention and Control. Antimicrobial resistance surveillance in Europe 2010. Annual Report of the European Antimicrobial Resistance Network (EARS-net). Stockholm: ECDC;2011. https:// ecdc.europa.eu/en/publications-data/antimicrobial-resistance-surveillanceeurope-2010. Accessed 05 Jan 2018.

9. Jarlier V, Trystram D, Brun-Buisson C, Fournier S, Carbonne A, Marty L, et al. Curbing methicillin-resistant Staphylococcus aureus in 38 French hospitals through a 15-year institutional control program. Arch Intern Med. 2010; 170(6):552-9.

10. Meyer E, Schroder C, Gastmeier P, Geffers C. The reduction of nosocomial MRSA infection in Germany: an analysis of data from the hospital infection surveillance system (KISS) between 2007 and 2012. Dtsch Arztebl Int. 2014; 111(19):331-6.

11. Walter J, Haller S, Blank HP, Eckmanns T, Abu Sin M, Hermes J. Incidence of invasive methicillin-resistant Staphylococcus aureus infections in Germany, 2010 to 2014. Euro Surveill. 2015;20(46):30067.

12. Walter J, Noll I, Weiss B, Claus H, Werner G, Eckmanns T, et al. Decline in the proportion of methicillin resistance among Staphylococcus aureus isolates from non-invasive samples and in outpatient settings, and changes in the co-resistance profiles; an analysis of data collected within the antimicrobial resistance surveillance network, Germany 2010 to 2015. BMC Infect Dis. 2017;17:169.

13. Guy R, Geoghegan L, Heginbotham M, Howe R, Muller-Pebody B, Reilly JS, et al. Non-susceptibility of Escherichia coli, Klebsiella spp., Pseudomonas spp., Streptococcus pneumoniae and Staphylococcus aureus in the UK: temporal trends in England, Northern Ireland, Scotland and Wales. J Antimicrob Chemother. 2016;71:1564-9.

14. Touraine M. Tackling antimicrobial resistance in France. Lancet. 2016; 387(10034):2177-9. https://doi.org/10.1016/50140-6736(16)30356-7.

15. Pfizer Limited. Tygacil summary of product characteristics. Sandwich, Kent; February, 2016.

16. Pfizer Inc. Wyeth Pharmaceuticals. Philadelphia: Tygaci® Product Insert: 2016. http://labeling.pfizer.com/showlabeling.aspx?id=491\&pagename= tygacil_fly.

17. Cattoir V, Dowzicky MJ. A longitudinal assessment of antimicrobial susceptibility among important pathogens collected as part of the Tigecycline Evaluation and Surveillance Trial (T.E.S.T.) in France between 2004 and 2012. Antimicrob Resist Infect Control. 2014;3:36. https://doi.org/ 10.1186/2047-2994-3-36

18. Clinical and Laboratory Standards Institute (CLSI). Methods for Dilution Antimicrobial Susceptibility Tests for Bacteria That Grow Aerobically; Approved standards - Tenth edition. CLSI Document M07-A10. Wayne, PA: CLSI; 2015.

19. Clinical and Laboratory Standards Institute (CLSI). Performance Standards for Antimicrobial Susceptibility Testing - Twenty-Sixth Informational Supplement. CLSI Document M100-S26. Wayne, PA: CLSI; 2016.

20. The European Committee on Antimicrobial Susceptibility Testing Breakpoint tables for interpretation of MICs and zone diameters. Version 7.1 2017. http://www.eucast.org. Accessed 04 Oct 2017.

21. Stefani S, Dowzicky MJ. Longitudinal assessment of antimicrobial susceptibility among gram-negative and gram-positive organisms collected from Italy as part of the Tigecycline evaluation and surveillance trial between 2004 and 2011. Pharmaceuticals. 2013;6:1381-406.

22. Chalfine A, Kitzis M-D, Bezie Y, Benali A, Perniceni L, Nguyen J-C, et al. Tenyear decrease of acquired methicillin-resistant Staphylococcus aureus 
(MRSA) bacteremia at a single institution: the result of a multifaceted program combining cross-transmission prevention and antimicrobial stewardship. Antimicrob Resist Infect Control. 2012;1 (1):18. https://doi.org/ 10.1186/2047-2994-1-18.

23. Gould IM. Treatment of bacteraemia: methicillin-resistant Staphylococcus aureus (MRSA) to vancomycin-resistant S. Aureus (VRSA). Int J Antimicrob Agents. 2013;42 Suppl:S17-21.

24. Birgy A, Levy $C$, Bidet $P$, Thollot F, Derkx V, Béchet $S$, et al. ESBL-producing Escherichia coli ST131 versus non-ST131: evolution and risk factors of carriage among French children in the community between 2010 and 2015. J Antimicrob Chemother. 2016;71:2949-56.

25. Dortet L, Cuzon G, Ponties V, Nordmann P. Trends in carbapenemaseproducing Enterobacteriaceae, France, 2012 to 2014. Euro Surveill. 2017; 22(6) https://doi.org/10.2807/1560-7917.

26. Robert J, Pantel A, Mérens A, Lavigne J-P, Nicolas-Chanoine $\mathrm{M}-\mathrm{H}$. On behalf of ONERBA's carbapenem resistance study group. Incidence rates of carbapenemase-producing Enterobacteriaceae clinical isolates in France: a prospective nationwide study in 2011-12. J Antimicrob Chemother. 2014;69:2706-12.

27. Jeannot K, Diancourt L, Vaux S, Thouverez M, Ribeiro A, Coignard B, et al. Molecular epidemiology of carbapenem non-susceptible Acinetobacter baumannii in France. PLoS One. 2014;9(12):e115452. https://doi.org/10.1371/ journal.pone.0115452.

28. Anonymous (2013). Réseau d'alerte, d'investigation et de surveillance des infections nosocomiales (Raisin). Enquête nationale de prévalence des infections nosocomiales et des traitements anti-infectieux en établissements de santé, France, mai-juin 2012. Résultats. Saint-Maurice: InVS; 2013. p. 181.

Ready to submit your research? Choose BMC and benefit from:

- fast, convenient online submission

- thorough peer review by experienced researchers in your field

- rapid publication on acceptance

- support for research data, including large and complex data types

- gold Open Access which fosters wider collaboration and increased citations

- maximum visibility for your research: over $100 \mathrm{M}$ website views per year

At BMC, research is always in progress.

Learn more biomedcentral.com/submissions 